UNIVERSITY OF GOTHENBURG

SCHOOL OF BUSINESS, ECONOMICS AND LAW

WORKING PAPERS IN ECONOMICS

No 549

\title{
The Persistence of Subjective Poverty in Urban Ethiopia
}

Yonas Alem, Gunnar Köhlin and Jesper Stage

December 2012

ISSN 1403-2473 (print)

ISSN 1403-2465 (online)

Department of Economics

School of Business, Economics and Law at University of Gothenburg

Vasagatan 1, PO Box 640, SE 40530 Göteborg, Sweden

+46 31786 0000, +46 317861326 (fax)

www.handels.gu.se info@handels.gu.se 


\title{
The persistence of subjective poverty in urban Ethiopia*
}

\author{
Yonas Alem ${ }^{\mathrm{a}}$ \\ Gunnar Köhlin ${ }^{\mathrm{b}}$ \\ Jesper Stage $e^{c}$
}

\section{December 2012}

\begin{abstract}
Using panel data spanning 15 years, this paper investigates the persistence and correlates of subjective and consumption poverty in urban Ethiopia. Despite the decline in consumption poverty in recent years, which has been linked to rapid economic growth, subjective poverty has remained largely unchanged. Dynamic probit regression results show that households with a history of past poverty continue to perceive themselves as poor even if their material consumption improves. Our results also suggest that the relative economic position of households is a strong determinant of subjective poverty, and having at least some type of employment reduces the likelihood that households will perceive themselves as poor, even if they remain in objective poverty. Receiving remittances from abroad, on the other hand, does not reduce perceived poverty, even if it raises material consumption. We argue that any analysis to measure the impact of growth on welfare should encompass subjective measures as well.
\end{abstract}

JEL Classification: I32; O12.

Keywords: Ethiopia, subjective poverty, dynamic probit

\footnotetext{
${ }^{\text {a }}$ Department of Economics, University of Gothenburg, PO Box 640, 40530 Gothenburg, yonas.alem@economics.gu.se.

${ }^{\mathrm{b}}$ Department of Economics, University of Gothenburg, PO Box 640, 40530 Gothenburg, gunnar.kohlin@economics.gu.se.

${ }^{\mathrm{c}}$ Department of Social Sciences, Mid Sweden University, 85170 Sundsvall, Jesper.Stage@miun.se.

*We would like to thank Magnus Hatlebakk, Adolf Mkenda and the participants at the Nordic Conference in Development Economics, University of Gothenburg, held on 18-19 June 2012; the seminar participants at the University of Dar es Salaam's Department of Economics staff seminar series; and participants at the 10th international conference on the Ethiopian economy, Addis Ababa, held on 19-21 July 2012, for very useful comments on earlier versions of the paper. Financial support from the Swedish International Development Agency (Sida) through the Environment for Development Initiative (EfD) of the Department of Economics, University of Gothenburg; from Elforsk; and from the Swedish Research Council Formas through the programme entitled Human Cooperation to Manage Natural Resources (COMMONS) is gratefully acknowledged. The views expressed in this paper are entirely those of its authors.
} 


\section{Introduction}

In this paper, we study determinants of subjective and objective poverty in urban Ethiopia from 1994 through 2009. Ethiopia has experienced high economic growth in the past decade, and objective poverty measures indicate that the poorest have also experienced rising living standards (see e.g. UNDP, 2011). Despite this, however, subjective poverty remains high; the share of households that perceive themselves as poor has barely changed at all in the same period (Figure 1). This reinforces the fact that poverty is sufficiently complex for it not to be captured using only objective, material measures.

(Figure 1 about here)

The fact that the share of the population perceiving themselves as poor has not been affected by increases in income and material consumption is a challenge to policy. ${ }^{1}$ Policymakers generally wish to maximise not the citizenry's material consumption, but rather some measure of the citizenry's well-being. If the poorer members of the population do not perceive themselves as better off now than they did ten years ago, this represents a policy failure. Thus, identifying the factors that determine citizens' own view of their poverty status may, from a policy perspective, be as important as identifying the determinants of their objective poverty status in terms of material consumption.

Using richer data and a richer econometric analysis than previously applied to this topic in a developing country, we are able to explore a larger set of possible determinants of subjective poverty than previous studies have done. In short, dynamic probit regression results suggest that households with a history of past poverty continue to perceive themselves as poor even if their material consumption improves. We also find that relative economic standing is a strong determinant of subjective poverty, and being engaged in any kind of income-generating

\footnotetext{
${ }^{1}$ The focus of this paper is on subjective poverty, or subjective well-being, related to capability and deprivation; the focus is not the broader, but more nebulous, concept of happiness. The general term life satisfaction or happiness extends beyond pure economic factors, and includes health, employment, marital status, democracy, belief in God, etc. See Dolan et al. (2008) for a detailed literature survey on happiness. However, it may well be argued that this concept is problematic from a policy perspective. Happiness is likely to have a broad range of determinants, many of which will only be amenable to policy interventions if policymakers are prepared to carry out highly paternalistic and intrusive policies. Along these lines, Ravallion and Lokshin (2002) argue that happiness is too broad to measure "economic welfare" and there is a possibility, for instance, for someone to be poor but happy, while someone else is rich but unhappy. Thus, if happiness is the policy target, policymakers should then give priority to increasing the well-being of the rich person - a conclusion which most people would find repugnant.
} 
job at all reduces the likelihood that households perceive themselves as poor, even if they remain in objective poverty. Results also show that receiving remittances from abroad does not reduce perceived poverty, even if it raises material consumption. We argue that any analysis to measure the impact of growth on citizens' welfare should encompass subjective measures as well.

The paper is structured in the following fashion: Section 2 discusses subjective poverty measurement and the perception of own poverty. Section 3 presents the econometric model and estimation strategy. Section 4 presents the data and descriptive statistics of variables. In section 5 we present results from alternative models for poverty persistence. Section 6 provides concluding remarks.

\section{Subjective poverty}

Following the classic work by Sen (e.g. 1982), the multidimensionality of poverty has been receiving increasing attention in research related to poverty. Multidimensional poverty extends beyond the ability to meet a minimum level of resources for daily needs as defined on the basis of income/consumption approaches to poverty. It is, rather, a broad concept that reflects the overlapping deprivations that an individual or a household experiences. Building on these blocks, Alkire and Santos (2010) constructed a multidimensional poverty index for 104 developing countries. Their measure incorporates health, education, and standard of living, which allows objective comparison with poverty figures computed according to measures of income. Alkire and Santos (ibid.) show that their index slightly overlaps with income poverty, but largely captures other, distinct aspects of poverty.

Much of the information used to construct income poverty measures for developing countries is obtained from household surveys. It is well documented that measurement errors due to imperfect recall and other practical problems related to constructing baskets of goods and poverty lines can seriously bias poverty indices (Browning et al., 2003; Deaton, 2010, 1997). More serious difficulties arise in constructing a standard poverty line for use in comparing poverty among different socio-economic groups and different countries. One of these difficulties is the need to correct for international price differences by using purchasing power parity exchange rates. Since countries differ in terms of relative prices and economic structures, distortions can be introduced into poverty measurement at a number of stages (Deaton, 2010). Given these problems, more reliable information can potentially be obtained by simply asking people directly about their poverty (ibid.). Such information can be used effectively to measure poverty over time and to make poverty comparisons. Furthermore, 
subjective poverty is multidimensional; and because it captures poverty in the different domains of one's life (Van Praag and Ferrer-i-Carbonell, 2006), it provides more information about deprivation.

We use subjective poverty data from households in urban Ethiopia to investigate the trends, persistence, and correlates of poverty over the past 15 years. Ethiopia has recently exhibited rapid economic growth, with the average annual real gross domestic product having grown by 11\% during 2004 to 2010 (IMF, 2012). This double-digit growth rate was, however, accompanied by a double digit inflation rate (15\% on average during the period), which appeared to have had adverse impacts on citizens' welfare (Alem and Söderbom, 2012). As we saw in Figure 1, objective poverty declined during this period, although subjective poverty remained high. This suggests that economic growth was not followed by improvement in the welfare of the multidimensional poor.

There are a number of reasons why people might continue to perceive themselves as poor even though their material income has increased. As noted above, there could be data problems that create an appearance of increased income and mask continued material poverty. Given the dramatic increase in income in Ethiopia, and given that the poorer segments of the population have clearly seen rising living standards as well, such data problems seem unlikely to be the only explanation, but it might at least form part of the picture. Studies of people's self-perception from other countries can be used to illuminate some other factors that could potentially matter. It is well known from previous studies (see e.g. Duesenberry, 1949, or Runciman, 1966, for seminal contributions) that people's self-perception is not only linked to absolute indicators; relative indicators, such as one's income relative to other people - and especially relative to one's perceived peers - also matter a great deal. Previous status will also matter; if a history of (objective and subjective) poverty leads people to perceive themselves as poor, this perception might remain after their material circumstances change. Dependence on others can also be problematic; experiences from other countries indicate that income transfers perceived as poverty support (e.g. food stamps or social welfare) can have negative impacts on a household's self-perception of poverty even though they raise the household's material well-being, whereas income transfers perceived as entitlements, such as pensions, are less problematic in this regard.

These fairly reasonable additional explanations for self-perceived poverty pose important methodological challenges. If the observed rise in living standards is in part a figment of poor price data, it is important to have detailed consumption statistics. If subjective poverty is linked to relative status, it becomes important to compare a household with others that are 
likely to be perceived as its peers. If subjective poverty is affected by previous poverty, there will be a hysteresis in self-perceived poverty such that households with the same material standards throughout the time span covered by a panel data set may nonetheless perceive themselves differently because of experiences prior to the start of the panel. If remittances which have increased dramatically in Ethiopia in the period studied here (see Alem, 2011) are perceived as poverty relief, they may have a negative impact on subjective poverty even as they raise the recipient household's material living standards. Thus, when analysing subjective poverty, one should ideally have sufficiently rich data to compare households with a wide range of others that are similar in occupation; one should have a panel that is sufficiently long in order to make unobserved household heterogeneities manageable; and one should be able to differentiate between various sources of income to such an extent that income sources which may be negative for the household's self-perception can be studied in isolation from the others.

Relatively speaking, more analysis has been done on the dynamics and persistence of poverty in rural areas of sub-Saharan Africa than in urban areas. Moreover, there are very few studies using subjective poverty measures, partly because of the methodological challenges outlined above and a lack of data that are sufficiently rich to deal with such challenges. One of the existing studies is that of Kingdon and Knight (2006), who develop and apply a method of using subjective information on well-being in order to measure poverty in South Africa. Using cross-sectional data, these authors show that the subjective well-being approach provides useful information for poverty analysis in poor countries. However, as they only had access to cross-sectional data, the issue of hysteresis in subjective poverty could not be explored. Furthermore, they did not study the role of economic position relative to peers, or the role of different income sources. Bigsten and Shimeles (2011), using a shorter (19942004) version of the panel data set used in this study, analyse the persistence of consumptionbased and subjective poverty in urban Ethiopia. In particular, in their investigation of whether or not covariates of these two poverty types differ, they found no significant differences. However, the divergence between subjective and objective poverty shown in Figure 1 above occurred mainly after the final round of the data set used in their study; their study, therefore, found a strong link between the two indicators - a link which is considerably weaker in the larger data set that we use. In addition, they did not control for several important variables such as international remittances, intra-household heterogeneity in labour market status, the different levels of education, and relative position of households. Given the discussion above, 
these may well be important determinants of perception about poverty, and therefore deserve consideration as well.

Our paper extends the analysis of subjective poverty by incorporating a new round of data which covers the period of drastic macroeconomic change during which subjective and objective poverty indicators diverged considerably. Our rich data set also lets us investigate other potentially important covariates that could play significant roles in poverty in the context of urban areas, such as household members' occupational characteristics, and international remittances. Furthermore, the paper uses a robust non-linear dynamic panel econometric technique - Wooldridge's conditional maximum likelihood estimator - which, in addition to taking care of the initial conditions problem encountered in such models, allows for possible correlation between unobserved time-invariant household characteristics and observable explanatory variables.

\section{Data and descriptive statistics of variables}

The study uses five rounds of panel data from four major urban areas of Ethiopia, namely the capital Addis Ababa, and Awassa, Dessie, and Mekelle. The data were collected in 1994, 1997, 2000, 2004 and 2009. The first four waves of the data were collected by the Department of Economics at Addis Ababa University in collaboration with the University of Gothenburg. ${ }^{2}$ A stratified sampling technique was used to form 1,500 households in total, which represent the urban population. The last wave of the data was collected in late 2008 and early 2009 by one of the authors from a subsample of the original households in the four cities, following a similar sampling strategy. ${ }^{3}$ Out of the 709 households surveyed in the 2009 round, 128 are new households chosen randomly and incorporated into the sample. These new households were surveyed to check the representativity of the panel households which were formed back in 1994. Alem and Söderbom (2012) check for this, and find no significant difference in welfare between the panel and the newly incorporated households conditional on observable household characteristics. This implies that the data reasonably represent urban Ethiopia. Given that our analysis involves estimation of a non-linear dynamic model, we use a balanced panel consisting of 366 households surveyed over the entire 15-year period of time.

\footnotetext{
${ }^{2}$ Data were also collected in 1995 . However, to maintain a fairly even gap between rounds, we dropped that survey from this wave. Refer to AAU and UG (1995) for details on the sampling strategy.

${ }^{3}$ Data were also collected from three other cities (Bahir Dar, Dire Dawa and Jimma) in earlier waves prior to 2009. Households in these cities were not surveyed in the 2009 round due to resource constraints. In any event, they represented only $20 \%$ of the original 1,500 households.
} 
Our subjective poverty measure is constructed from responses to the question Do you consider yourself as rich, middle-income, or poor? The responses allowed us to classify households as either Poor or Non-poor. ${ }^{4}$ Following conventional practice, we compute our objective poverty head count using consumption expenditure data. The definition of consumption used in the analysis is comprehensive, and incorporates both food and non-food components. Food consumption includes the value of food purchased from the market and food obtained in the form of gifts or aid. The non-food component includes expenditure on clothing, energy, education, kitchen equipment, contributions, health, education, and transportation. Following Ravallion and Bidani (1994), we use the cost-of-basic-needs approach to construct poverty lines. This involves estimating the food poverty line based on the cost of a basket of goods that yields the minimum energy of 2,200 kcal needed per person per day as stipulated by World Health Organization, and making adjustments for the non-food component. ${ }^{5}$ This was done for each round and city. We then constructed price indices by using the poverty line of Addis Ababa in the base year (1994), relative to which all the poverty lines in each city and round were expressed. ${ }^{6}$ Thereafter we used the price indices constructed to convert nominal consumption expenditure to real expenditure, adjusting for both spatial and temporal price differences. We also took account of household size for economies of scale, and of differences in needs by using adult equivalent units. Thus, we could classify as Poor those households whose real consumption expenditure per adult equivalent units was below the capital city's poverty line in 1994.

Given that we had to exclude some of the panel households in 2009 due to resource constraints to cover survey costs, there could be valid reasons to be worried about the possibility of attrition. We attempted to address this issue by specifically identifying those households that were surveyed in 2004 but excluded in the 2009 survey, and by running simple models of the probability of poverty. Our results, presented in Appendix A, show that the dummy variable for households who were excluded in the year 2009 is not statistically significant at any level. This indicates that the panel households excluded in the latest round were not systematically different in terms of either type of poverty, which gives us the confidence to argue that attrition has not resulted in any meaningful bias in our sample.

Descriptive statistics are presented in Table 1. It can be seen that objective poverty has been declining steadily since 1994 . Subjective poverty, on the other hand, has barely changed

\footnotetext{
${ }^{4}$ In other words, the question was related to deprivation, not to the broader concept of life satisfaction.

${ }^{5}$ Refer to Alem (2011) for "basket of goods" used in the analysis and for details on the construction of the poverty line.

${ }^{6}$ Ravallion (1998) provides a detailed discussion on the construction of price indices from poverty lines.
} 
at all. The difference between the two poverty measures has, therefore, increased fairly steadily throughout the period and, in the latest round of the survey, was the highest it had ever been. This reinforces the fact that subjective poverty encompasses other dimensions of poverty often not incorporated by money-metric poverty measures. It is clear that, despite rising material living standards, numerous households who are no longer below the poverty line continue to perceive themselves as poor.

Table 1 about here

\section{Econometric framework}

It is a well-established fact in the poverty literature that an individual or a household who is poor in a certain period is more likely to be poor in the next: there is state dependence in poverty (see e.g. Alem, 2011; Biewen, 2009; Bigsten \& Shimeles, 2008; Duncan et al., 1993; Giraldo et al., 2006; Mejer and Linden, 2000; OECD, 2001; Oxley et al., 2000). ${ }^{7}$ Therefore, we model the current state of poverty as a function of lagged poverty, i.e. poverty in the previous period. In addition, there are unobserved (and time-invariant) household or individual characteristics such as personal motivation, parental effects, rate of time preference, and risk aversion parameters that make specific groups prone to poverty, which should be taken into account. Consequently, we specify a dynamic model of the probability of being poor (either in subjective or objective terms) as -

$$
s_{i t}^{*}=\gamma s_{i t-1}+x_{i t}^{\prime} \beta+\eta_{i}+u_{i t}
$$

where the subscript $i=1, \ldots, N$ indexes households; the subscript $t=2, \ldots, T$ indexes time periods; $s_{i t}^{*}$ is a latent dependent variable for being in poverty; $x_{i t}$ is a vector of explanatory variables; $\eta_{i}$ is a term capturing unobserved household-specific random effects; $u_{i t}$ is a

\footnotetext{
${ }^{7}$ Biewen (2009) points out five possible reasons for a true state dependence in poverty: (i) lack of incentive to continue working or refusal to take up a job when earnings from a job are too low; (ii) deterioration of human capital during a spell of unemployment, which can eventually lead to demoralisation and loss of motivation to find and take up a new job; (iii) social exclusion due to poverty and low income, which may lead to problems of addiction to drugs and alcohol, which in turn could lead to deteriorating health conditions and, hence, difficulties finding a better-paying job; (iv) the tendency of accepting welfare support during unemployment as a way of living, and consequently losing the incentive to look for a betterpaying job; and (v) inability to engage in marriage or cohabitation during unemployment or chronic poverty, which could reduce the possibility of economies of scale in consumption within a household, and increase the risk of poverty.
} 
random error term assumed to be normally distributed, $\mathrm{N}\left(0, \sigma_{u}^{2}\right)$, and $\gamma \& \beta$ are parameters to be estimated. The observed binary outcome variable is -

$$
s_{i t}= \begin{cases}1 & \text { if } s_{i t}^{*}>0 \\ 0, \text { otherwise }\end{cases}
$$

In the standard random effects probit model, it is assumed that, conditional on $x_{i t}, \eta_{i t}$ is normally distributed with mean zero and variance, $\sigma_{\eta}^{2}$, and independent of $u_{i t}$ and $x_{i t} .{ }^{8}$ Thus, more precise estimates than the pooled probit can be obtained from the random effects probit model, which takes into account the correlation between the composite error $\epsilon_{i t}=\eta_{i}+u_{i t}$ terms in any two periods. ${ }^{9}$ Given the assumptions above, the probability $P$ that household $i$ is poor at time $t$, given $\eta_{i}$, is specified as -

$$
P\left[s_{i t} \mid x_{i t}, s_{i t-1}, \eta_{i}\right]=\Phi\left[\left(\gamma s_{i t-1}+x_{i t}^{\prime} \beta+\eta_{i}\right)\left(2 s_{i t}-1\right)\right]
$$

where $\Phi$ is the cumulative distribution function of the standard normal distribution. An important econometric issue that needs to be addressed is the so-called initial conditions problem. This problem arises because the start of the observation period (1994) does not coincide with the start of the stochastic process generating households' poverty experiences. Thus, estimation of the model requires a further assumption about the relationship between the initial period's poverty status $s_{i 1}$ and $\eta_{i}$. If the initial conditions are correlated with $\eta_{i}$, as is likely in our context, using the standard random effects probit model - which assumes the former to be exogenous - will lead to overstating the magnitude of state dependence, i.e. the estimate of $\gamma$ will be larger than what it actually should be. To take care of this problem and to estimate the model consistently, the unobserved household heterogeneity term should be integrated out.

One possible approach to solve the initial conditions problem is based on a two-step maximum likelihood estimator suggested by Heckman (1981), who was the first to address the problem. Heckman's approach starts by specifying a linearised reduced-form equation for the initial value of the latent variable, as follows:

\footnotetext{
${ }^{8}$ This implies that $\eta_{i}$ is uncorrelated with $x_{i t}$. However, correlation can be allowed (Mundlak, 1978; Chamberlain, 1984) by including $x_{i t}=\left(x_{i 0}, \ldots, x_{i T}\right)$ or, alternatively, averages of the $x$ variables over time as additional regressors in the model.

${ }^{9}$ The correlation between any two time periods can be shown to be $\lambda=\operatorname{corr}\left(\epsilon_{i t}, \epsilon_{i s}\right)=\frac{\sigma_{\alpha}^{2}}{\sigma_{\alpha}^{2}+\sigma_{u}^{2}} \quad t, s=2, \ldots, T ; t \neq s$.
} 


$$
s_{i 1}^{*}=z_{i 1}^{\prime} \pi+\theta_{1} \eta_{1}+u_{i 1}
$$

where $\theta>0 ; \eta_{1}$ and $u_{i}$ are independent of each other; and $(i=1, \ldots, N)$. The vector $z$ includes exogenous instruments that include the initial values of the explanatory variables (i.e. $\left.x_{i 1}\right)$. In addition, it is assumed that the $u_{i t}$ are independent of $\eta_{i}$, and that both are distributed normally with variance 1 and $\sigma_{\eta}^{2}$, respectively. Given equations (1) and (4), most applied researchers assume fixed correlation between $\left(\theta_{1} \eta_{1}+u_{i 1}\right)$ and the error terms in the equations for other periods (Arulampalam and Stewart, 2009).

Given serially uncorrelated random error terms, the likelihood function $L$ to be maximised for household $i$, given $\eta_{1}$, can be specified as -

$$
\begin{aligned}
L_{i}=\int\{ & \Phi\left[\left(z_{i 1}^{\prime} \pi+\theta_{1} \eta_{1}\right)\left(2 s_{i t}-1\right)\right] \\
& \left.\times \prod_{t=2}^{T_{i}} \Phi\left[\left(x_{i t}^{\prime} \beta+\gamma s_{i t-1}+\theta_{t} \eta\right)\left(2 s_{i t}-1\right)\right] g(\eta) d \eta\right\}
\end{aligned}
$$

where $g(\eta)$ represents the probability density functions of $\eta_{i}$. With the assumption of normality in the distribution of $\eta$, the Gauss-Hermite quadrature (Butler and Moffitt, 1982) can be used to evaluate the integral. However, the use of this estimator has been limited due to its huge computational time cost during estimation.

Another approach to deal with the initial conditions problem in non-linear dynamic panel data models is the Wooldridge conditional maximum likelihood (WCML) estimator proposed by Wooldridge (2005). This approach involves integrating out the household unobserved heterogeneity term $\eta$ through specifying an approximation of its density conditional on $s_{i 1}$. Let the joint density for the observed sequence of the dependent variable $\left(s_{2}, s_{3}, \ldots, s_{T}, \mid s_{1}\right)$ be written as $\left(s_{T}, s_{T-1}, \ldots, s_{2} \mid s_{1}, x, \eta\right)$. To integrate $\eta$ out, Wooldridge suggests the specification

$$
\eta_{i} \mid s_{1}, z \approx N\left(\zeta_{0}+\zeta_{1} s_{i 1}+z^{\prime} \zeta+a_{i}, \sigma_{\eta}^{2}\right)
$$

where 


$$
\eta_{i}=\zeta_{0}+\zeta_{1} s_{i 1}+z^{\prime} \zeta+a_{i}
$$

The correlation between $s_{i 1}$ and $\eta_{i}$ is alleviated in equation (7) by introducing a new unobservable term $a$ that is uncorrelated with the initial observation $s_{i 1}$.

Substituting equation (7) into equation (1) yields -

$$
P\left(s_{i t}=1 \mid a_{i}, s_{i 1}\right)=\Phi\left[\left(x_{i t}^{\prime} \beta+\gamma s_{i t-1}+\zeta_{1} s_{i 1}+z^{\prime} \zeta+a_{i}\right)\right] \quad t=2 \ldots, T
$$

Consequently, the likelihood function to be maximised for household $i$ is given by -

$$
L_{i}=\int\left\{\prod_{t=2}^{T} \Phi\left[\left(x_{i t}^{\prime} \beta+\gamma s_{i t-1}+\zeta_{1} s_{i 1}+z^{\prime} \zeta+a_{i}\right)\left(2 s_{i t}-1\right)\right]\right\} g^{*}(a) d a
$$

where $g^{*}(a)$ is the normal probability density function of the new unobservable term $a_{i}$ introduced in equation (7). Free correlation between the initial condition and error terms in other periods (as is the case in Heckman's estimator) can be allowed by introducing a set of time dummies interacted with $s_{i l}$. Estimation is straightforward using standard software. ${ }^{10}$ Apart from the ease of using standard software for making estimates, the Wooldridge Conditional Maximum Likelihood (CML) estimator allows for correlation between $x_{i t}$ and $\alpha_{i}$ following Mundlak (1978), overcoming the strong assumptions of a random effects model. We therefore use this estimator to analyse the persistence of subjective and objective poverty in urban Ethiopia. As it is estimated as a random effect probit, which corrects for the initial conditions problem and allows correlation between the explanatory variables and the unobserved individual heterogeneity term, interpretation of the marginal effects is straightforward.

\section{Results}

Estimates of the dynamic probit models for the probability of being in subjective and objective poverty are given in Table 2 . Columns 1 and 2 show the standard random effects estimator, which treats initial conditions as exogenous for the respective incidence of

\footnotetext{
${ }^{10}$ Another approach to addressing the initial conditions problem is the two-stage estimator developed by Orme (2001, 1997). It involves specifying an approximation for $\mu_{i}$ which is used to replace it by another unobservable component that is uncorrelated with the initial observation. This is achieved by controlling for the residual of the simple probit estimator for the initial period in the main dynamic probit model, and running it as a random effects probit. In our case, however, the results from this estimator were not significantly different from the random effects probit model; hence, we chose not to report them.
} 
subjective and objective poverty. Columns 3 and 4 present the same estimates from Wooldridge's CML estimator. The coefficient of the lagged dependent variable for both types of poverty in all models is statistically significant, but the magnitude declines drastically once we control for endogeneity of initial conditions using the Wooldridge CML estimator. This estimator also allows for possible correlation between the unobserved heterogeneity term and the explanatory variables. The corresponding marginal effects from all the estimators are presented in Table 3.

Table 2 about here

Table 3 about here

Although there is a difference in the incidence of subjective and objective poverty, as shown in the previous section, there appear to be similarities in the effect of some correlates on the two poverty types. There is state dependence in both types of poverty, indicating that a household which is poor in one round is more likely to be in poverty during the next period as well. However, the magnitude of state dependence is lower when using the Wooldridge estimator in comparison with the standard random effects estimators. The marginal effects from the WCML estimators presented in Column 3 of Table 3 show that a household which perceives itself as poor in any previous period has a $6.7 \%$ higher probability of feeling poor in the next period. The marginal effect on the next period of being consumption-poor in any prior period is $7.9 \%$.

The strong impact of initial poverty on both types of poverty is clearly evident from the WCML estimator. Not only is the impact strong, but it is also larger than the coefficient of the state dependence parameter for both types of poverty - supporting the importance of controlling for endogeneity of initial conditions. On average, a household which was subjectively poor in the initial period (1994) has a 7\% greater probability of feeling poor in the years that follow.

When it comes to the role of other covariates, age has a non-linear effect on subjective poverty; also, a household headed by a male individual reduces the probability of that household feeling poor; however, neither the age nor the male-head-of-household variable has a significant effect on consumption poverty in urban Ethiopia. We also note that the relative position of households is an important and strong determinant of subjective poverty. A household whose real per capita consumption expenditure is less than the cluster median per 
capital consumption has a $19.8 \%$ greater probability of feeling poor. ${ }^{11}$ As indicated by the statistically significant coefficients for all three dummy variables for education (except primary education on objective poverty), being headed by educated individuals reduces the likelihood of being in either type of poverty. In fact, the largest marginal effects are exhibited by the education variables. For instance, compared with households headed by illiterate individuals (the reference group), households headed by an individual who has completed tertiary level schooling have a $23.4 \%$ lower likelihood of feeling poor. The impact on consumption poverty is the largest as well, with such households being $20.8 \%$ less likely to be in consumption poverty. ${ }^{12}$

One interesting finding is that some of the other household members' occupational and demographic characteristics have different effects on the two types of poverty. These variables exhibit positive association with objective poverty, probably indicating the positive impact of household size and higher dependency ratio on the incidence of consumption poverty. The impact of some of these variables on subjective poverty is, however, negative. Column 3 of Table 3 shows that households with a higher number of self-employed (ownaccount) and civil/public sector workers have a strong and lower likelihood of being out of subjective poverty. ${ }^{13}$ However, having more own-account household members has a positive impact on consumption poverty. This probably implies that engaging in some kind of incomegenerating job reduces the likelihood of feeling poor although it does not help the household to be out of consumption poverty - which reinforces the fact that subjective poverty captures other dimensions of deprivation. Finally, one notes that households receiving international remittances have a lower likelihood of being in consumption poverty as documented by regression results from the WCML estimator (Column 4 of Table 2). However, according to the results from the Wooldridge model, remittances have no impact on a household's own view of whether it is poor or not.

\footnotetext{
${ }^{11}$ Following the arguments presented in Section 2, we control for relative position of households only in the probability model of subjective poverty, as this variable is not expected to affect objective poverty. We created a dummy variable for households with a per capita consumption level that was lower than the woreda (district) median per capita consumption expenditure. We hypothesise that households compare themselves with others in the same geographic location - in our case, the same woreda.

${ }^{12}$ It should be noted that every additional variable included here, compared with those studied in Bigsten and Shimeles (2011), has an impact either on objective poverty, subjective poverty, or both.

${ }^{13}$ Alem (2011) documents that a large proportion of self-employed (own-account worker) household members in urban Ethiopia are engaged in low-paying small businesses. For instance, in 2009, 67\% were engaged in activities such as petty trading and preparing and selling food and drinks.
} 


\section{Conclusions}

In this paper we use panel data from urban Ethiopia spanning 15 years to investigate the trends, persistence and correlates of subjective and objective poverty. Ethiopia experienced rapid economic growth in recent years although growth was accompanied by a double-digit inflation rate. Descriptive statistics show that, following economic growth, consumption poverty consistently declined while subjective poverty remained high.

We find that the initial level of poverty matters considerably for future poverty. Once we control for this persistent poverty, we find that temporary spells of poverty have little impact on future poverty, be it subjective or objective. Consistent with previous literature on subjective well-being, we find that the relative position of households in their respective communities is a statistically strong determinant of, and has a large impact on, subjective poverty. We also find that households with a higher number of self-employed and civil/public sector worker members have a lower likelihood of feeling poor, even though having a larger number of self-employed household members actually increases the likelihood of being objectively poor. These findings reinforce the fact that subjective poverty captures other dimensions of deprivation, and suggest that engaging in some kind of income-generating job reduces the likelihood of feeling poor, regardless of whether the job has any actual impact on consumption. Households receiving international remittances have a lower likelihood of being in objective poverty, but are just as likely as other similar households to perceive themselves as poor, suggesting that the household's self-image is not improved even when material conditions improve.

We argue that it is possible for a household to be above the money-metric poverty line through support from relatives and friends, but still feel deprived; at the same time, activities that do not help consumption status may nonetheless help the household's perception of being in control of its own destiny. Therefore, any analysis related to measuring the welfare impact of economic growth, and any policies aimed at ensuring that the benefits of growth are widely shared, should encompass subjective measures as well. 


\section{References}

AAU \& UG/Addis Ababa University and University of Gothenburg, 1995. Report on the 1994 Socio-economic Survey of Major Urban Centers in Ethiopia. Addis Ababa University.

Alem, Y., 2011. Poverty Dynamics and Intra-household Heterogeneity in Occupations: Evidence from Urban Ethiopia. Department of Economics, University of Gothenburg, Gothenburg.

Alem, Y., Söderbom, M., 2012. Household-level consumption in urban Ethiopia: The effects of a large food price shock. World Development, 40, 146-162.

Alkire, S., Santos, M. E., 2010. Acute Multidimensional Poverty: A New Index for Developing Countries. Department of International Development, University of Oxford, Oxford.

Arulampalam, W., Stewart, M., 2009. Simplified implementation of the Heckman estimator of the dynamic probit model and a comparison with alternative estimators. Oxford Bulletin of Economics and Statistics, 71(5), 659-681.

Biewen, M., 2009. Measuring state dependence in individual poverty histories when there is feedback to employment status and household composition. Journal of Applied Econometrics, 24(7), 1095-1116.

Bigsten, A., Shimeles, A., 2008. Poverty transition and persistence in Ethiopia. World Development, 36(9), 1559-1584.

Bigsten, A., Shimeles, A., 2011. The persistence of urban poverty in Ethiopia: A tale of two measurements. Applied Economics Letters, 18, 835-839.

Browning, M., Crossley, T.F. Weber, G., 2003. Asking consumption questions in general purpose surveys. Economic Journal, 113, F540-F567.

Butler, J.S., Moffitt, R., 1982 A computationally efficient quadrature procedure for the onefactor multinomial probit model. Econometrica. 50(3), 761-764.

Chamberlain, G., 1984. Panel data, in: Griliches, Z., Intrilligator, M. (Eds.), Handbook of Econometrics, Vol. 2. North Holland, Amsterdam, pp. 1254-1318.

Deaton, A., 1997. The Analysis of Household Surveys: A Microeconomic Approach to Development Policy. Johns Hopkins University Press, Baltimore.

Deaton, A., 2010. Price indices, inequality, and the measurement of world poverty. Presidential Address, American Economic Association, January, Atlanta. 
Dolan, P., Peasgood, T., White, M., 2008. Do we really know what makes us happy? A review of the economic literature on the factors associated with subjective well-being. Journal of Economic Psychology, 29, 94-122.

Duncan, G.J., Gustafsson, B., Hauser, R., Schmauss, G., Messinger, H., Muffels, R., Nolan, B., Ray, J.C., 1993. Poverty dynamics in eight countries. Journal of Population Economics, 6(3), 215-234.

Duesenberry, J.S., 1949. Income, Saving, and the Theory of Consumer Behavior. Harvard University Press, Harvard.

Giraldo, A., Rettore, E., Trivellato, U., 2006. The persistence of poverty: True state dependence or unobserved heterogeneity? Some evidence from the Italian Survey on Household Income and Wealth. Paper presented at the 27th General Conference of the International Association for Research in Income and Wealth, Stockholm, Sweden, 1824 August 2002.

Heckman, J.J., 1981. The incidental parameters problem and the problem of initial conditions in estimating a discrete time-discrete data stochastic process, in: Manski, C.F., McFadden, D.L. (Eds.), Structural Analysis of Discrete Data and Econometric Applications. IT Press, Cambridge, MA, pp. 114-178.

IMF/International Monetary Fund. 2012. World Economic Outlook Database, accessed, August, 2012.

Kingdon, G.G., Knight, J. 2006. Subjective well-being poverty vs. income poverty and capabilities poverty? Journal of Development Studies, 42(7), 1199-1224.

Mejer, L., Linden, G., 2000. Persistent income poverty and social exclusion in the European Union. Statistics in Focus, Population and Social Conditions, Theme 3, 13/2000.

Mundlak, Y., 1978. On the pooling of time-series and cross-sectional data. Econometrica 46(1), 69-85.

OECD/Organisation for Economic Co-operation and Development, 2001. Employment Outlook, OECD, Paris, Ch. 2.

Orme, C.D., 1997. The initial conditions problem and two-step estimation in discrete panel data models. Mimeo, University of Manchester.

Orme, C.D., 2001. Two-step inference in dynamic non-linear panel data models. Mimeo, University of Manchester. 
Oxley, H., Dang, T.T., Antolin, P., 2000. Poverty dynamics in six OECD countries. OECD Economic Studies, No. 30, 2000/I, 7-52.

Ravallion, M., 1998. Poverty lines in theory and practice. Living Standards Measurement Study Working Paper No. 133.

Ravallion, M., Bidani, B., 1994. How robust is a poverty profile? The World Bank Economic Review, 8(1), 75-102.

Ravallion, M., Lokshin, M., 2002. Self-rated economic welfare in Russia. European Economic Review, 46(8), 1453-1473.

Runciman, W.G., 1966. Relative deprivation and social justice: a study of attitudes to social inequality in twentieth-century England. University of California Press, Berkeley.

Sen, A., 1982. Poverty and Famines: An Essay on Entitlements and Deprivation. Clarendon Press, Oxford.

UNDP/United Nations Development Programme, 2011. Human Development Report 2011. United Nations Development Programme, Washington, DC.

Van Praag, B., Ferrer-i-Carbonell, A., 2006. A multi-dimensional approach to subjective poverty, in: Kakwani, S. and Silber, J. (Eds.), Quantitative Approaches to Multidimensional Poverty Measurement. Palgrave MacMillan, Houndmills.

Wooldridge, J.M., 2005. Simple solutions to the initial conditions problem in dynamic, nonlinear panel data models with unobserved heterogeneity. Journal of Applied Econometrics, 20, 39-54. 
Table 1: Descriptive statistics of variables over time

\begin{tabular}{|c|c|c|c|c|c|c|c|c|c|c|}
\hline \multirow[b]{2}{*}{ Variable } & \multicolumn{2}{|c|}{1994} & \multicolumn{2}{|c|}{1997} & \multicolumn{2}{|l|}{2000} & \multicolumn{2}{|c|}{2004} & \multicolumn{2}{|c|}{2009} \\
\hline & Mean & $\begin{array}{l}\text { Standard } \\
\text { deviation }\end{array}$ & Mean & $\begin{array}{l}\text { Standard } \\
\text { deviation }\end{array}$ & Mean & $\begin{array}{l}\text { Standard } \\
\text { deviation }\end{array}$ & Mean & $\begin{array}{l}\text { Standard } \\
\text { deviation }\end{array}$ & Mean & $\begin{array}{l}\text { Standard } \\
\text { deviation }\end{array}$ \\
\hline Household - subjectively poor & 0.55 & 0.50 & 0.54 & 0.50 & 0.53 & 0.50 & 0.49 & 0.50 & 0.51 & 0.50 \\
\hline Household - consumption-poor & 0.46 & 0.50 & 0.41 & 0.49 & 0.38 & 0.49 & 0.35 & 0.48 & 0.31 & 0.46 \\
\hline $\begin{array}{l}\text { Household per capita consumption less than cluster } \\
\text { median }\end{array}$ & 0.51 & 0.50 & 0.53 & 0.50 & 0.49 & 0.50 & 0.51 & 0.50 & 0.49 & 0.50 \\
\hline Head - age & 48.86 & 12.97 & 48.17 & 13.55 & 51.09 & 13.43 & 52.27 & 13.86 & 55.63 & 14.52 \\
\hline Head - male & 0.58 & 0.49 & 0.56 & 0.50 & 0.55 & 0.50 & 0.50 & 0.50 & 0.49 & 0.50 \\
\hline Head - female* & 0.42 & 0.49 & 0.44 & 0.50 & 0.45 & 0.50 & 0.50 & 0.50 & 0.51 & 0.50 \\
\hline Head - primary schooling completed & 0.41 & 0.49 & 0.43 & 0.50 & 0.30 & 0.46 & 0.27 & 0.44 & 0.30 & 0.46 \\
\hline Head - secondary schooling completed & 0.26 & 0.44 & 0.25 & 0.44 & 0.52 & 0.50 & 0.30 & 0.46 & 0.28 & 0.45 \\
\hline Head - tertiary education completed & 0.06 & 0.24 & 0.06 & 0.23 & 0.04 & 0.20 & 0.07 & 0.25 & 0.10 & 0.30 \\
\hline Head - illiterate* & 0.27 & 0.44 & 0.26 & 0.44 & 0.14 & 0.35 & 0.36 & 0.48 & 0.32 & 0.47 \\
\hline Head - employer or own-account worker & 0.31 & 0.46 & 0.31 & 0.46 & 0.25 & 0.44 & 0.26 & 0.44 & 0.23 & 0.42 \\
\hline Head - civil/public servant & 0.20 & 0.40 & 0.18 & 0.39 & 0.16 & 0.36 & 0.13 & 0.34 & 0.11 & 0.31 \\
\hline Head - private sector employee & 0.05 & 0.21 & 0.04 & 0.20 & 0.09 & 0.29 & 0.08 & 0.27 & 0.13 & 0.34 \\
\hline Head - casual worker & 0.14 & 0.35 & 0.15 & 0.36 & 0.10 & 0.31 & 0.07 & 0.25 & 0.06 & 0.24 \\
\hline Head - out of the labour force* & 0.30 & 0.46 & 0.32 & 0.47 & 0.39 & 0.49 & 0.46 & 0.50 & 0.46 & 0.50 \\
\hline No. of own-account worker members & 0.16 & 0.60 & 0.15 & 0.54 & 0.23 & 0.73 & 0.19 & 0.49 & 0.22 & 0.47 \\
\hline No. of civil/public servant members & 0.37 & 0.81 & 0.29 & 0.66 & 0.11 & 0.34 & 0.33 & 0.62 & 0.28 & 0.59 \\
\hline No. of private sector employee members & 0.17 & 0.52 & 0.20 & 0.55 & 0.30 & 0.60 & 0.42 & 0.76 & 0.68 & 0.97 \\
\hline No. of casual worker members & 0.14 & 0.42 & 0.13 & 0.38 & 0.17 & 0.52 & 0.17 & 0.50 & 0.22 & 0.59 \\
\hline No. of unemployed members & 0.75 & 1.04 & 0.65 & 0.96 & 0.66 & 1.02 & 0.74 & 1.09 & 0.37 & 0.76 \\
\hline No. of out-of-the-labour-force members & 1.48 & 1.42 & 1.36 & 1.31 & 1.69 & 1.49 & 1.51 & 1.32 & 1.70 & 1.60 \\
\hline No. of children & 2.34 & 1.83 & 2.50 & 1.82 & 1.86 & 1.60 & 1.47 & 1.38 & 1.00 & 1.11 \\
\hline No. of elderly & 0.13 & 0.37 & 0.10 & 0.32 & 0.06 & 0.31 & 0.03 & 0.18 & 0.06 & 0.24 \\
\hline Household receives international remittances & 0.04 & 0.19 & 0.06 & 0.24 & 0.11 & 0.32 & 0.13 & 0.34 & 0.31 & 0.46 \\
\hline Resides in Addis & 0.80 & 0.40 & 0.80 & 0.40 & 0.80 & 0.40 & 0.80 & 0.40 & 0.80 & 0.40 \\
\hline Observations & 366 & & 366 & & 366 & & 366 & & 366 & \\
\hline
\end{tabular}

* Reference group 
Table 2: Life satisfaction regressions: Results from alternative ordered probit estimators

\begin{tabular}{|c|c|c|c|c|c|c|c|c|}
\hline & \multicolumn{2}{|c|}{$\begin{array}{c}1 . \\
\text { SREPR }\end{array}$} & \multicolumn{2}{|c|}{$\begin{array}{c}2 . \\
\text { OREPR }\end{array}$} & \multicolumn{2}{|c|}{$\begin{array}{c}3 . \\
\text { SWCML }\end{array}$} & \multicolumn{2}{|c|}{$\begin{array}{c}4 . \\
\text { OWCML }\end{array}$} \\
\hline & Coefficient & SE & Coefficient & SE & Coefficient & SE & Coefficient & SE \\
\hline Lagged poverty & $0.440 * * *$ & 0.103 & $0.77 * * *$ & 0.080 & $0.226 * *$ & 0.117 & $0.307 * *$ & 0.133 \\
\hline Relative position & $0.718 * * *$ & 0.086 & - & - & $0.670 * * *$ & 0.091 & - & - \\
\hline Head - age & -0.021 & 0.016 & -0.01 & 0.020 & $-0.044 *$ & 0.023 & 0.025 & 0.025 \\
\hline Age of head squared $* 100$ & 0.019 & 0.015 & 0.007 & 0.014 & $0.042 *$ & 0.022 & -0.021 & 0.024 \\
\hline Head - male & $-0.219 * *$ & 0.092 & $-0.16 * *$ & 0.090 & $-0.214 * *$ & 0.101 & -0.111 & 0.110 \\
\hline Head - primary schooling completed & $-0.293 * * *$ & 0.103 & $-0.24 * *$ & 0.100 & $-0.289 * * *$ & 0.109 & -0.120 & 0.114 \\
\hline Head - secondary schooling completed & $-0.469 * * *$ & 0.116 & $-0.40 * * *$ & 0.110 & $-0.426 * * *$ & 0.121 & $-0.299 * *$ & 0.130 \\
\hline Head - tertiary education completed & $-0.890 * * *$ & 0.201 & $-0.96 * * *$ & 0.230 & $-0.795 * * *$ & 0.214 & $-0.813 * * *$ & 0.278 \\
\hline Head - employer or own-account worker & 0.002 & 0.104 & -0.140 & 0.100 & 0.0003 & 0.112 & -0.102 & 0.118 \\
\hline Head - civil/public servant & 0.010 & 0.132 & $-0.30 * *$ & 0.140 & 0.064 & 0.140 & $-0.284 *$ & 0.156 \\
\hline Head - private sector employee & 0.218 & 0.156 & 0.080 & 0.150 & 0.195 & 0.165 & 0.131 & 0.174 \\
\hline Head - casual worker & $0.262 *$ & 0.152 & 0.030 & 0.140 & 0.237 & 0.160 & -0.003 & 0.164 \\
\hline No. of own-account worker members & $-0.113 *$ & 0.066 & $0.18 * * *$ & 0.060 & $-0.320 * * *$ & 0.096 & $0.190 * *$ & 0.092 \\
\hline No. of civil/public servant members & $-0.364 * * *$ & 0.074 & -0.100 & 0.070 & $-0.295 * * *$ & 0.095 & 0.055 & 0.098 \\
\hline No. of private sector employee members & $-0.131 * *$ & 0.053 & -0.050 & 0.050 & $-0.120 *$ & 0.069 & 0.066 & 0.074 \\
\hline No. of casual worker members & 0.123 & 0.078 & $0.37 * * *$ & 0.080 & -0.007 & 0.095 & $0.277 * * *$ & 0.099 \\
\hline No. of unemployed members & 0.003 & 0.041 & $0.16^{* * *}$ & 0.040 & -0.008 & 0.054 & $0.245^{* * *}$ & 0.056 \\
\hline No. of out-of-the-labour-force members & $-0.090 * * *$ & 0.029 & $0.13 * * *$ & 0.030 & -0.026 & 0.041 & $0.265^{* * *}$ & 0.043 \\
\hline No. of children & $-0.055^{* *}$ & 0.028 & $0.19 * * *$ & 0.030 & $-0.087 * *$ & 0.043 & $0.236 * * *$ & 0.045 \\
\hline No. of elderly & -0.007 & 0.142 & 0.090 & 0.140 & 0.024 & 0.189 & 0.121 & 0.200 \\
\hline Household receives international remittances & $-0.277 * *$ & 0.112 & $-0.60 * * *$ & 0.120 & -0.006 & 0.143 & $-0.376 * *$ & 0.165 \\
\hline Resides in Addis Ababa & 0.056 & 0.101 & $0.27 * * *$ & 0.100 & $0.196^{*}$ & 0.117 & $0.280 * *$ & 0.128 \\
\hline Year 2000 & 0.058 & 0.110 & 0.070 & 0.110 & 0.029 & 0.116 & -0.014 & 0.124 \\
\hline Year 2004 & -0.104 & 0.111 & 0.070 & 0.110 & -0.166 & 0.120 & -0.041 & 0.129 \\
\hline Year 2009 & 0.068 & 0.122 & 0.170 & 0.120 & -0.076 & 0.140 & -0.051 & 0.152 \\
\hline Initial poverty status & - & - & - & - & $0.236 * *$ & 0.108 & $0.510 * * *$ & 0.129 \\
\hline Log-likelihood & -812.96 & & -740.28 & & -771.39 & & -677.92 & \\
\hline Obs & 1464 & & 1464 & & 1464 & & 1464 & \\
\hline
\end{tabular}


Table 3: Marginal effects - computed from Table 2

\begin{tabular}{|c|c|c|c|c|c|c|c|c|}
\hline & \multicolumn{2}{|c|}{$\begin{array}{c}1 . \\
\text { SREPR }\end{array}$} & \multicolumn{2}{|c|}{$\begin{array}{c}2 . \\
\text { OREPR }\end{array}$} & \multicolumn{2}{|c|}{$\begin{array}{c}3 . \\
\text { SWCML }\end{array}$} & \multicolumn{2}{|c|}{$\begin{array}{c}4 . \\
\text { OWCML }\end{array}$} \\
\hline & $\mathrm{dy} / \mathrm{dx}$ & SE & $\mathrm{dy} / \mathrm{dx}$ & SE & $\mathrm{dy} / \mathrm{dx}$ & $\mathrm{SE}$ & $\mathrm{dy} / \mathrm{dx}$ & SE \\
\hline Lagged poverty & $0.139 * * *$ & 0.032 & $0.219 * * *$ & 0.02 & $0.067 * *$ & 0.035 & $0.079 * *$ & 0.035 \\
\hline Relative position & $0.226 * * *$ & 0.025 & - & - & $0.198 * * *$ & 0.025 & - & - \\
\hline Head - age & -0.007 & 0.005 & -0.003 & 0.004 & $-0.013 *$ & 0.007 & 0.006 & 0.006 \\
\hline Age of head squared $* 100$ & 0.006 & 0.005 & 0.002 & 0.004 & $0.012 *$ & 0.007 & -0.005 & 0.006 \\
\hline Head - male & $-0.069 * *$ & 0.029 & $-0.046^{*}$ & 0.025 & $-0.063 * *$ & 0.030 & -0.028 & 0.028 \\
\hline Head - primary schooling completed & $-0.092 * * *$ & 0.032 & $-0.068 * * *$ & 0.029 & $-0.085 * * *$ & 0.032 & -0.031 & 0.029 \\
\hline Head - secondary schooling completed & $-0.148 * * *$ & 0.036 & $-0.116 * * *$ & 0.032 & $-0.126 * * *$ & 0.035 & $-0.076 * *$ & 0.033 \\
\hline Head - tertiary education completed & $-0.281 * * *$ & 0.062 & $-0.275^{* * *}$ & 0.065 & $-0.234 * * *$ & 0.062 & $-0.208 * * *$ & 0.071 \\
\hline Head - employer or own-account worker & 0.001 & 0.033 & -0.041 & 0.029 & 0.00007 & 0.033 & -0.026 & 0.030 \\
\hline Head - civil/public servant & 0.003 & 0.042 & $-0.085 * *$ & 0.039 & 0.019 & 0.041 & $-0.073 *$ & 0.040 \\
\hline Head - private sector employee & 0.069 & 0.049 & 0.022 & 0.043 & 0.058 & 0.048 & 0.034 & 0.045 \\
\hline Head - casual worker & $0.083^{*}$ & 0.048 & 0.007 & 0.041 & 0.070 & 0.047 & -0.001 & 0.042 \\
\hline No. of own-account worker members & $-0.036^{*}$ & 0.021 & $0.052 * * *$ & 0.018 & $-0.094 * * *$ & 0.028 & $0.049 * *$ & 0.024 \\
\hline No. of civil/public servant members & $-0.115 * * *$ & 0.023 & -0.028 & 0.02 & $-0.087 * * *$ & 0.028 & 0.014 & 0.025 \\
\hline No. of private sector employee members & $-0.041 * *$ & 0.017 & -0.014 & 0.015 & $-0.035 *$ & 0.020 & 0.017 & 0.019 \\
\hline No. of casual worker members & 0.039 & 0.025 & $0.107 * * *$ & 0.021 & -0.002 & 0.028 & $0.071 * * *$ & 0.025 \\
\hline No. of unemployed members & 0.001 & 0.013 & $0.047 * * *$ & 0.011 & -0.002 & 0.016 & $0.063 * * *$ & 0.014 \\
\hline No. of out-of-the-labour-force members & $-0.028 * * *$ & 0.009 & $0.038 * * *$ & 0.008 & -0.008 & 0.012 & $0.068 * * *$ & 0.011 \\
\hline No. of children & $-0.017 *$ & 0.009 & $0.056 * * *$ & 0.007 & $-0.026 * *$ & 0.013 & $0.060 * * *$ & 0.011 \\
\hline No. of elderly & -0.002 & 0.045 & 0.027 & 0.039 & 0.007 & 0.056 & 0.031 & 0.051 \\
\hline Household receives international remittances & $-0.087 * * *$ & 0.035 & $-0.171 * * *$ & 0.034 & -0.002 & 0.042 & $-0.096 * *$ & 0.042 \\
\hline Resides in Addis Ababa & 0.018 & 0.032 & $0.078 * * *$ & 0.028 & $0.058^{*}$ & 0.034 & $0.072 * *$ & 0.033 \\
\hline Year 2000 & 0.018 & 0.035 & 0.021 & 0.032 & 0.009 & 0.034 & -0.004 & 0.032 \\
\hline Year 2004 & -0.033 & 0.035 & 0.02 & 0.032 & -0.049 & 0.035 & -0.010 & 0.033 \\
\hline Year 2009 & 0.021 & 0.039 & 0.048 & 0.035 & -0.022 & 0.041 & -0.013 & 0.039 \\
\hline Initial poverty status & - & - & - & - & $0.070 * *$ & 0.031 & $0.131 * * *$ & 0.031 \\
\hline
\end{tabular}

Note: $\mathrm{S}$ and $\mathrm{O}$ stand for subjective and objective indicators, respectively; REPR is the Random Effects Probit estimator; WCML is the Wooldridge CML estimator; $* * * \mathrm{p}$ $<0.01 ; *$ p $<0.05, * \mathrm{p}<0.1$ 


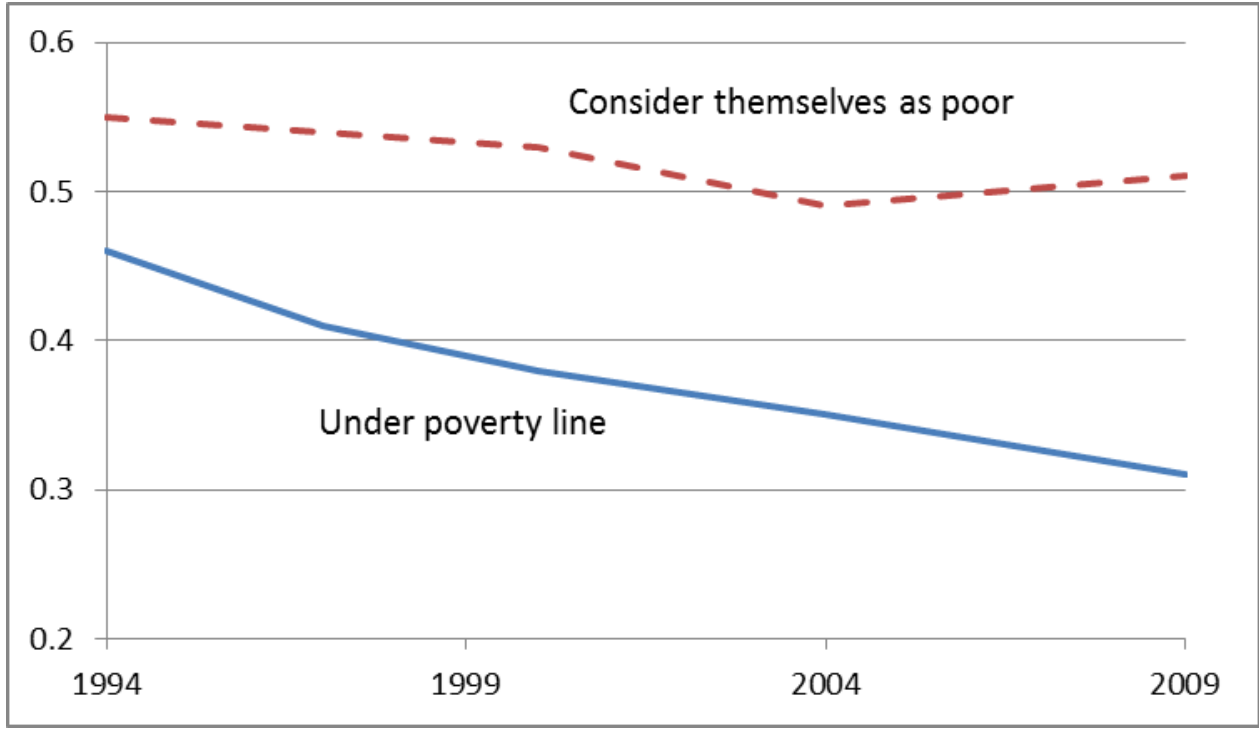

Figure 1: Trends in urban poverty, 1994-2009. Source: Authors' calculations based on survey discussed in text. 
Appendix A: Determinants of subjective and objective poverty, 2009

\begin{tabular}{lllll}
\hline \hline & Coef. & SE & Coef. & SE \\
\hline Relative position & $0.756^{* * *}$ & 0.092 & - & - \\
Head - age & -0.015 & 0.018 & 0.016 & 0.019 \\
Age of head squared * 100 & 0.009 & 0.017 & -0.022 & 0.018 \\
Head - male & -0.074 & 0.1 & -0.061 & 0.105 \\
Head - primary schooling completed & -0.045 & 0.115 & $-0.299^{* * *}$ & 0.114 \\
Head - secondary schooling completed & $-0.455^{* * *}$ & 0.132 & $-0.741 * * *$ & 0.134 \\
Head - tertiary education completed & $-0.914^{* * *}$ & 0.204 & $-1.360^{* * *}$ & 0.247 \\
Head - employer or own-account worker & $-0.186^{*}$ & 0.116 & 0.112 & 0.117 \\
Head - civil/public servant & -0.179 & 0.141 & -0.101 & 0.155 \\
Head - private sector employee & 0.137 & 0.163 & 0.09 & 0.167 \\
Head - casual worker & $0.355^{* *}$ & 0.174 & $0.397 * *$ & 0.172 \\
No. of own-account worker members & -0.081 & 0.092 & 0.123 & 0.094 \\
No. of civil/public servant members & $-0.401 * * *$ & 0.077 & $-0.190^{* * *}$ & 0.081 \\
No. of private sector employee members & $-0.199 * * *$ & 0.061 & -0.066 & 0.062 \\
No. of casual worker members & $0.231^{* * *}$ & 0.096 & $0.223^{* * * *}$ & 0.085 \\
No. of unemployed members & -0.012 & 0.041 & $0.195^{* * *}$ & 0.04 \\
No. of out-of-the-labour-force members & $-0.148^{* * *}$ & 0.034 & $0.115^{* * *}$ & 0.034 \\
No. of children & -0.044 & 0.032 & $0.194 * * *$ & 0.033 \\
No. of elderly & -0.105 & 0.207 & 0.292 & 0.21 \\
Household receives international remittances & $-0.573^{* * *}$ & 0.13 & $-0.760^{* * *}$ & 0.152 \\
Resides in Addis Ababa & $0.238^{* *}$ & 0.105 & $0.182^{*}$ & 0.109 \\
Attrition 2009 & -0.034 & 0.088 & -0.072 & 0.091 \\
Intercept & $0.754^{*}$ & 0.466 & $-0.915^{*}$ & 0.513 \\
\hline Pseudo-R ${ }^{2}$ & 0.207 & & & 0.186 \\
Log-likelihood & -613.907 & & & -567.859 \\
Observations & 1118 & & & 1118 \\
\hline \hline & & & & \\
\hline \hline
\end{tabular}

